\title{
Socialização e violência policial militar
}

\author{
A gnaldo José da Silva*
}

\begin{abstract}
R esumo: Este trabalho lusca, a partir dbs conceitos de instituição total e mortificação do self de Erving Gof fman, analisar o processo de socialização do policial militar. Partimos do pressuposto que a socialização policial militar, centrada nos valores e princípios da hierarquia e da disciplina, anula antigos valores da vida civil de seus novos membros, forjanob-lhes uma nova identidade, de aunho eminentemente militar .Assim, ao receber uma socialização centrada na hierarquia e disciplina militares, os novos membros da Polícia Militar constroem uma visão estereotipada dos civis, representandb-os como paisanos folgados, um termo depreciativo. Nessa perspectiva, o civil passa a ser representadb de forma pejorativa, primeiro passo para a violência policial militar. Dessa forma, estabelecemos, analiticamente, um elo de ligação entre o processo de socialização e a trualência policial militar no trato com a comunidade.
\end{abstract}

Palavras-chave: instituição total; Polícia Militar; socialização.

Este artigo é fruto de uma pesquisa ${ }^{1}$ vinculada ao Programa de M estrado em Sociologia da U niversidade Federal de Goiás (UFG), realizada na A cademia de Polícia M ilitar do Estado de Goiás (APM-GO), na cidade de Goiânia, entre os anos de 2001 e 2002. A intenção era compreender o processo de socialização dos policiais militares, através de um estudo sobre o Curso de Formação de Praças Policiais Militares (CFPPM), mais conhecido como CFP ou Curso de Soldado e, ao mesmo tempo, perceber uma possível relação entre a formação militar e as práticas policiais. 0 pressuposto de que partimos é que o processo de socialização policial militar, centrado nos princípios e valores do militarismo, a hierarquia e a disciplina, contribui para um tipo específico

\footnotetext{
* Doutorando em Sociologia pela UnB, mestre em Sociologia pela UFG e professor da Faculdade Padrão - Goiânia.

1. A pesquisa em si constou de: 1) um levantamento bibliográfico em torno das monografias do Curso de A perfeiçoamento de Oficiais (CAO), com vistas a apreender a visão que os oficiais tinham da Polícia Militar e, em específico, dos praças; 2) 21 entrevistas junto aos alunos do curso de soldado que, ao todo, eram 114, e 3) acompanhamento e observações em sala de aula.
}

de comportamento policial, o violento. Para tal, recorremos a Erving G offman, a fim de que, à Iuz do conceito de instituição total, pudéssemos analisar o processo de socialização policial militar. $^{2}$

\section{Instituição total}

Neste estudo, consideramos a A cademia de Polícia Militar como uma instituição total, termo apropriado de Erving Goffman (1974) para definir as instituições que exibem alto grau de fechamento e que produzem um modo de vida paralelo ao da sociedade mais ampla. Os internos, em tais instituições, estão inseridos num "mundo para si", onde eles dormem, trabal ham e recreiam. Durante o processo de socialização, o contato com o mundo externo é mínimo, às vezes inexistente. No processo de socialização dos PM s em tais instituições ocorre

\footnotetext{
2. Temos ciência de que o processo de socialização policial militar não se esgota no período de formatura, ele vai além e acompanha o policial ao longo de sua carreira. No entanto, esta análise restringe-se ao período de formação, por ser ele o que marca a ruptura entre dois mundos sociais: 0 civil e 0 militar.
} 
o que Goffman denomina de mortificação do self, ${ }^{3}$ ou seja, a anulação da identidade individual, principal mente nos primeiros dias de adaptação.

De acordo com G offman, "uma instituição total pode ser definida como um local de residência e trabalho onde um grande número de indivíduos com situação semelhante, separados da sociedade mais ampla por considerável período de tempo, leva uma vida fechada e formalmente administrada" (1974, p. 11).

$\mathrm{N}$ a perspectiva de Goffman, todas as instituições tendem a ser fechadas. Esse fechamento diz respeito ao caráter totalizador que se expressa em barreiras que cerceiam as livres relações de quem está dentro com quem está fora dessas instituições. Essas barreiras e proibições incluem o aspecto físico, como é o caso das prisões, dos campos de concentração, dos conventos e dos quartéis.

Goffman levanta cinco tipos ou categorias de instituições totais. Em síntese são locais estabelecidos: 1) para cuidar de pessoas incapazes e inofensivas (ex.: asilos e orfanatos); 2) para cuidar de pessoas que oferecem, não intencionalmente, algum tipo de ameaça à comunidade (ex.: sanatórios e leprosários); 3) para proteger a sociedade contra perigos intencionais (ex.: prisões); 4) para real izar mais adequadamente uma tarefa (ex.: quartéis e escolas internas); 5) para servir de refúgio do mundo (ex.: mostei ros e conventos). Este estudo privilegiou a quarta categoria, aquela instituída para real izar de maneira mais adequada al guma tarefa de trabalho.

A A cademia de Polícia M ilitar foi concebida e tratada como uma instituição total. Vale lembrar que uma das características fundamentais das instituições totais é que, nelas, diferentemente do que ocorre na sociedade moderna, o indivíduo tende a dormir, trabal har e recrear em um mesmo ambiente. Ou seja, enquanto o indivíduo da sociedade mais ampla recreia, trabal ha e dorme em lugares diferentes, o indivíduo participante de uma instituição total faz tudo isso num mesmo local.

3. A tradução brasileira de Goffman (1974) é mortificação do eu. N este trabalho, no entanto, foi feita a opção de usar self em lugar de eu, já que self diz respeito à parte social que o indivíduo apropria para construir sua identidade.
A o conceber a A cademia de Polícia M ilitar como instituição total, torna-se necessário afirmar que, na Polícia M ilitar de Goiás, havia, até pouco tempo atrás, um período de adaptação, no qual os alunos PM s viviam em regime de internato. Para os cadetes, esse período era de um ano, no qual só aos finais de semana eram liberados, caso não estivessem escalados para al gum tipo de serviço.

No que diz respeito à formação dos alunos soldados, a norma de aquartelização nunca foi rígida, senão implicitamente. Para esses alunos principal mente, epara os policiais militares como um todo, costuma-se afirmar que o quartel é a segunda casa e que PM só tem horário para começar a trabalhar, mas não para terminar.

U m outro ditado corrente nas fal as dos PM S, principalmente dos oficiais, éque o policial militar é "polícia 24 horas por dia". Parece não haver diferença entre trabalho e folga, entre lugar de trabalhar e lugar de dormir. 0 policial militar assume e incorpora tão bem essas instruções de seus colegas que até mesmo os seus vizinhos e amigos o chamam em momentos de folga para resolver qualquer questão pendente. Portanto, parece não haver grandes problemas em conceber a A cademia de Polícia M ilitar como instituição total, já que as barrei ras que separam três esferas da vida, local de trabalho, de lazer e de dormir, são fluidas, inexistentes ou estão fragilizadas e diluídas pelo comportamento dos policiais militares. 0 grau de fechamento da Polícia M ilitar não chega ao extremo, como é o caso das penitenciárias. Nem por isso, pode-se afirmar que não haja barreiras dificultando 0 contato e a comunicação dos internos com 0 mundo externo.

Um outro aspecto relevante das instituições totais é que existe uma distinção básica entre dois grupos: um pequeno grupo dirigente e uma grande massa de internos. Na Polícia M ilitar, pode-se identificar a equipe dirigentecom os oficiais e o grupo dos internos com os praças. $\mathrm{N}$ este trabal ho, concebemos os cadetes como parte integrante da equipe dirigente e os alunos do CFP como internos.

Esses dois grupos, equipe dirigente e internos, constituem categorias genéricas de identificação profissional da corporação. A pretensão não é reduzir nem desfigurar 0 
complexo hierárquico da Polícia M ilitar nesses dois grupos gerais. Não ignoramos a existência de uma complexa cadeia de poder e influência nas relações entre os diferentes integrantes da Polícia M ilitar, uns exercendo mais, outros menos influência em suas redes de relações. A pesar do grupo de internos não ser homogêneo, seus integrantes têm em comum o fato de serem "pontas-de-lança", termo usado por alguns oficiais para designar os policiais que lidam diretamente com as ocorrências policiais militares e com as pessoas nelas envolvidas.

F eita a distinção entre equipe dirigente e internos, cabe dizer que, segundo Goffman, "cada um desses grupos percebe 0 outro através de estereótipos limitados e hostis" (1974, p. 19). Numa instituição total, as decisões são tomadas apenas pela equipe dirigente. $0 \mathrm{~s}$ planos de trabalhos da Polícia Militar, decididos nas reuniões de oficiais, descem prontos à tropa. Ordem é para ser cumprida, esta é a regra. As ponderações, pontos de vista e discordâncias dos subordinados são ignoradas por completo. Evidentemente, todas essas restrições, a começar pela comunicação, ajudam a manter um clima hostil entre os grupos. A pesar dos valores militares tentarem agregar todos os policiais dentro de um único bloco, percebe-se que os dois grupos têm pontos de vista bastante distintos.

Sobre a equi pe dirigente recaem a responsabilidade e o controle de muitas necessidades humanas de grupos inteiros de pessoas. $\mathrm{Na}$ Polícia M ilitar, não é diferente, ao menos durante o período de adaptação dos PM s à instituição. A ação dos oficiais, sobretudo dos cadetes, em se tratando de uma instituição de ensino, sufoca a individualidade ea liberdade de ação dos alunos soldados, forjando-Ihes uma identidade eminentemente militar.

$\mathrm{N}$ as organizações modernas, 0 direito legítimo de interpretar e julgar as ações de funcionários, baseando-se nos regulamentos internos, recai sobre a equipe dirigente. $\mathrm{Na}$ Polícia M ilitar, no entanto, não são incomuns situações complexas nas quais o superior impõese ao subordinado, independentemente do que está estatuído.

Conceber a Polícia Militar como uma instituição total implica avaliar as redes de contato e comunicação entre equipe dirigente e grupo de internos. No caso, o contato e o diálogo entre oficiais e praças são, muitas vezes, dificultados por parte dos primeiros, em nome da hierarquia e da disciplina. A ssim, "presumivelmente, todas essas restrições de contato ajudam a conservar os estereótipos antagônicos" (Goffman, 1974, p. 20).

A abordagem de Goffman a respeito das instituições totais teve, em nosso estudo, a vantagem de facilitar a percepção e a análise da relação entre socialização e prática policial militar. ${ }^{4}$ Os PM s, ao serem socializados num ambiente de relações hostis, o quartel, acabam reproduzindo tais embates nas suas interações com a sociedade mais ampla. Ou seja, já que, nas rel ações internas dos PM s entre si, o diálogo é quase inexistente, o clima é de hostilidade e 0 relacionamento é baseado, muitas vezes, no autoritarismo e no abuso de poder por parte dos superiores hierárquicos, o mesmo tenderá a ocorrer no convívio com a comunidade. Dessa forma, o relacionamento precário e autoritário entre policiais militares e comunidade vinculase ao processo de socialização dos primeiros num mundo onde as relações entre oficiais e praças são hostis.

No entanto, as idéias não mudam bruscamente, é necessário um longo processo, no qual os indivíduos vão se socializando e incorporando os valores e normas do grupo. Na Polícia M ilitar, como em qualquer instituição total, esse processo é acelerado pela mortificação do self durante a permanência do interno na instituição, principalmente na fase da adaptação, período em que ele é considerado novato. U m outro fator que parece contribuir para catalisar esse processo de mortificação do self é que a maioria dos indivíduos que ingressam na Polícia Militar é relativamente jovem, não tendo ainda cristalizado al guns valores e princípios sociais tidos como imprescindíveis na sociedade moderna democracia, cidadania, igualdade, entre outros.

\footnotetext{
4. Vale ressaltar que a relação entre socialização e práticas policiais militares, sobretudo aquelas marcadas pela truculência, não é mecânica e nem mesmo fácil de ser percebida. 0 vínculo que estabelecemos entre socialização e violência não deve supor, também, que estamos querendo reduzir todos os componentes que concorrem para a truculência policial militar a apenas um, a socialização.
} 
Essa imaturidade quase sempre se traduz na rápida absorção e internal ização dos valores e preceitos militares, presente nas interações entre equipe dirigente e internos.

U ma outra observação deve ser feita. A ssim como as idéias e valores não são incorporados da noite para o dia, da mesma forma também as práticas policiais não são puro reflexo da vida em quartel. Quando se trata de relações sociais, as coisas não funcionam mecanicamente. Há uma complexa trama de elementos objetivos e subjetivos, internos e externos, interagindo, orientando e reorientando o comportamento dos indivíduos em sociedade.

De modo geral, o policial militar tem consciência de que é participante de uma formação distinta daquela transmitida aos civis. A ssim, ele se vê como um ser capaz de um autocontrole inatingível pelos não-participantes dos valores e princípios militares. No linguajar dos PMs, ouve-se muito o termo paisano folgado, ou seja, o civil é folgado justamente por não ter recebido a formação militar e, portanto, não sabe se comportar de forma disciplinada como eles. 0 termo paisano "é normalmente usado em lugar de 'civil' mas, embora pareça ser a mesma coisa, não é. 'Paisano' é um termo claramente pejorativo [...]" (Castro, 1990, p. 38).

$\mathrm{N}$ a relação entre Polícia M ilitar e comunidade, os PM s constroem estereótipos ou model os de comportamento para as pessoas da comunidade, baseando-se nos valores militares, ou seja, aquel es enfatizados durante o processo de socialização policial militar. Esses estereótipos ou representações criam certas expectativas nos PM s em relação ao comportamento dos civis de uma determinada comunidade. Tais expectativas, geralmente, não correspondem à visão de mundo dos civis, gerando um desnível de comunicação e relacionamento entre uns e outros, o que pode resultar em violência policial.

Essas representações construídas socialmente durante o CFP referem-se à expectativa de que os civis se comportem como os policiais militares que aprendem a ter uma postura e uma compostura rígidas desde os primeiros dias na escola de formação. A ssim como os PM s de baixa ou nenhuma graduação têm de se submeter aos superiores hierárquicos, também os PM s, quando em serviço, principal mente operacional, esperam que os paisanos folgados se submetam a eles com o mesmo respeito e submissão.

\section{M ortificação do self}

O conceito de alternação biográfica de Peter B erger (1995) revelou-se útil no auxílio e na busca da compreensão do processo de socialização dos policiais militares. A alternação diz respeito à tomada de consciência do indivíduo ao passar de um mundo social a outro. "Isto é, modificamos nossas cosmovisões (e, portanto, nossas interpretações e reinterpretações de nossa biografia) à medida que passamos de um mundo social para outro" (Berger, 1995, p. 75).

Ao mudar de mundo social, o indivíduo reinterpreta sua biografia e, portanto, sua identidade. Para ilustrar essa afirmação, recorro a um exemplo pessoal: em 1989, quando cumpria o serviço militar obrigatório no Exército, após uma semana de incansáveis exercícios e treinamento intensivo, em ritmo al ucinante, das 6 às 22 horas, vivendo internamente, saí e, ao entrar em um ônibus, senti al go diferente, senti ser um militar. 0 modo como segurei no corrimão daquele ônibus foi totalmente diferente do costumeiro. A vibração, isto é, a ênfase nos exercícios militares daquela semana tinha me contagiado. N os termos de B erger, a consciência sociológica permitiu-me perceber tal alternação, ou seja, a mudança de mundo social.

A quelas primeiras semanas no Exército, a quarentena, apresentavam a todos os novatos um novo mundo. 0 s antigos valores deveriam ser destruídos ou, pelo menos, sufocados, contidos. Criava-se assim uma nova identidade, a de militar. Os treinamentos daquela quarentena serviram para despir todos os novatos de hábitos, costumes e vícios herdados da antiga vida civil. Naqueles primeiros dias de quartel, era difícil um que não chorasse. A pesar dos exercícios físicos serem cansativos ao extremo, o que mais incomodava era a pressão psicológica. Assim, um sargento batia no armário e apitava enquanto dava três minutos para que uma companhia inteira tomasse banho (cerca de 120 homens). D urante as primeiras semanas no quartel era comum ouvirem-se frases de 
soldados durante o sono. Não era difícil escutar às quatro horas da manhã um soldado gritando, enquanto dormia, "sim, senhor", "pronto" e outras expressões de obediência. Dessa forma, "apesar da pressão revestir-se por vezes de um caráter 'físico', como nos exemplos dados, os cadetes afirmam que ela é basicamente 'psicológica'. Seu componente mais forte seria a humilhação verbal" (Castro, 1990, p. 16).

Durante a quarentena, as punições eram sem dó para aqueles que não aprendiam a mortificar 0 antigo ser que havia em si. Era necessário que todos aprendessem as regras básicas do militarismo: dizer sim, senhor e não, senhor, executar as ordens sem questioná-las. Saber o seu lugar dentro do complexo hierárquico era de fundamental importância para uma boa convivência.

Parece que todo aquel e esforço para despir, de antigos hábitos, todos os novatos surtiu al gum efeito. No Exército, sobretudo no mês de chegada do novato, conhecido como quarentena, todas as expressões de sentimento esensibilidade eram contidas e sufocadas. Com o passar do tempo, no entanto, al guns sol dados trabal havam mal-humorados a ponto de soarem 0 alarme de sua guarita apenas para descarregar suas tensões. Outros disparavam suas armas e depois al egavam terem visto algum vulto ou qualquer coisa se movendo. A pesar de haver essas fugas, elas não eram comuns na fase de adaptação. Elas ocorriam na medida em que os soldados tornavam-se mais antigos dentro da caserna.

$\mathrm{N}$ a Polícia M ilitar, não é muito diferente, já que a estrutura dessa instituição segue o mesmo modelo da do Exército. $\mathrm{N}$ as academias e centros de formação policial militar são os valores inerentes à estrutura militar, isto é, à hi erarquia e à disciplina os mais relevantes. É ensinado aos alunos em formação que o soldado é superior ao tempo, ou seja, o sol dado está preparado para enfrentar qualquer situação, seja ela natural (vento, chuva calor etc.) ou social (conflitos, motins etc.). 0 policial militar é superior ao tempo porque ele possui um corpo disciplinado. ${ }^{5}$

5. 0 corpo disciplinado revela que o treinamento militar possibilita aos PM s o adestramento do corpo, de forma a superar qualquer tipo de humilhação ou circunstância constrangedora. 0 termo é de Michel Foucault e foi usado por Da Silva, 1998.
A té recentemente havia nos $\operatorname{cursos}^{6}$ de formações de policiais militares os chamados arranca-rabos, um tipo de castigo em forma de treinamento militar que consistia em atividades humilhantes como rastejar, ficar sentado e de pé ao som do apito do instrutor, marchar com fuzil até 0 aluno não suportar, em resumo, cumprir atividades humilhantes, mas que eram eficazes para a mortificação do self. A lguém que não passasse pelo menos por um arranca-rabo era chacoteado pelos próprios colegas como sendo um paisano fardado. De certa forma, o arranca-rabo pode ser equiparado a rito de passagem, ${ }^{7}$ uma cerimônia que marca o momento de transição de um mundo social a outro. Nessas situações particulares, porém reveladoras, o aluno era submetido a tratamentos humilhantes. Os oficiais, nessas ocasiões, al cançavam uma total submissão dos alunos que, sob qualquer pressão, precisavam suportar as humilhações, caso quisessem permanecer ligados ao curso, e qualquer desobediência poderia resultar no desligamento ou em punições que, além de cercear a liberdade, manchavam sua ficha pessoal.

$N$ ão se pode deixar de registrar que atualmente existem as manobras, os aquartelados e outras atividades que, apesar de não serem designadas de arranca-rabos, têm, muitas vezes, conteúdos semelhantes a estes. $\mathrm{N}$ ão importa o nome que se dêa tais atividades, seja arranca rabo ou manobra, o que deve-se destacar é que são eficazes para anular valores da vida civil e implantar um novo código de conduta, pautado nos princípios da hierarquia e da disciplina.

Nesse processo de mortificação do self, os valores estruturantes da Polícia Militar vão sendo incorporados à maneira de pensar e agir

\footnotetext{
6. Vale ressaltar que somente na década de 1990 é que os cursos de soldado passaram a ser realizados apenas na Academia de Polícia Militar (APM) e no Centro de Formação e A perfeiçoamento de Praças (CFAP); até então, os cursos de soldado eram realizados nas diversas unidades que compõe a Polícia Militar do Estado de Goiás, no interior e na capital. Isto pressupõe que praticamente todos os oficiais eram "instrutores" nos cursos, quer estivessem preparados ou não.

7. C.L. A lbuquerque e E.P. M achado (2001) fazem uma análise dos rituais da instituição policial militar, mostrando que a modernização do currículo do CFO da PM da Bahia não dispensa os ritos de mortificação e anulação total do indivíduo, durante a Jornada de Instrução M ilitar (JIM).
} 
dos PMs, de tal forma que não é necessário fazer um grande esforço para identificar um policial militar, mesmo estando fora de serviço e sem nenhum tipo de fardamento. A sua fala, os seus gestos, o seu comportamento, tudo isso o denuncia como tal. A ssim, uma das funções do processo de mortificação do self é fazer com que o indivíduo rompa com valores e sensibilidades do velho mundo social de que participava para que possa se apropriar com maior nitidez dos novos valores.

No processo de socialização policial militar, os exercícios, ordens, tarefas e qualquer outro tipo de atividade mortificam o self dos referidos alunos em formação e aceleram a passagem de um mundo social a outro, e 0 úl timo estado é considerado superior ao primeiro. Em outras palavras, o papel de militar deve sobrepor-se aos papéis antes desempenhados por esse mesmo indivíduo na sociedade mais ampla. Os valores, as crenças e as ideologias presentes nas leis, regulamentos, costumes e tradições da Polícia M ilitar vão sendo assimilados de tal forma que o status social de seu antigo mundo cede lugar a um novo status, o de militar.

Nesse período de adaptação, Goffman afirma que há uma "[...] deformação pessoal que decorre do fato de a pessoa perder seu conjunto de identidade [...]" (1974, p. 29). Na construção da nova identidade dos PM s, o papel de militar sobrepõe-se tanto aos princípios e valores vinculados ao seu "antigo mundo" como também ao próprio papel de policial. A ntes de ser um bom policial, é necessário ser um bom militar, saber obedecer, colocar-se no seu lugar. 0 militarismo deixa de ser apenas um meio, torna-se um fim em si mesmo.

No processo de mortificação do self, "muitas vezes, os internos são obrigados a, em sua interação social com a equipe dirigente, apresentar atos verbais de deferência - como, por exemplo, dizendo 'senhor' a todo momento" (idem, ibidem, p. 30). A relação entre equipe dirigente e internos é marcada por um certo descaso. Alguns oficiais e cadetes sentem-se como se tivessem uma natureza superior à dos al unos soldados, assim como os pastores estão, por natureza, numa posição mais el evada que suas ovelhas.
0 fato de haver diferentes refeitórios, cassinos e alojamentos para praças e oficiais corrobora a idéia de apartação entre esses dois grupos da Polícia M ilitar. Essa separação e distanciamento, além do tratamento hostil que superiores dispensam aos subalternos, reforça a idéia compartilhada entre os internos de que a equipe dirigente não os considera como iguais, ${ }^{8}$ em alguns casos nem mesmo como seres humanos.

\section{Dupla ester eotipia}

A pesar do discurso, ${ }^{9}$ principalmente dos oficiais, e dos ensinamentos transmitidos em sala de aula a respeito de construir uma polícia mais humana e mais democrática, a forma de socialização imposta aos alunos do Curso de Formação de Praças Policiais M ilitares, através dos ritos, Ordem Unida e arranca-rabos, contradiz esses ensinamentos e discursos reticentes, forjando uma imagem pejorativa do civil.

A visão hierarquizada do policial militar a respeito do civil tem a sua contrapartida no fato de que os civis também representam os policiais militares de forma pejorativa, ocorrendo uma dupla estereotipia. Por um lado, o civil é visto como um paisano folgado. Por outro, a população vê o policial militar como alguém despreparado, rude e violento.

Parcelas significativas da sociedade criam estereótipos negativos a respeito da Polícia Militar. As classes abastadas, pelo fato de a polícia ser uma profissão mal remunerada, com pouca sofisticação cultural por parte de seus integrantes e ser uma profissão eminentemente das classes mais baixas da sociedade. Já as pessoas das classes mais baixas, devido às suas próprias experiências negativas com a Polícia Militar. ${ }^{10}$

8. Iguais no sentido amplo do termo, como um princípio da sociedade moderna e não como uma igualdade hierárquica. 9. Discurso observado na pesquisa empírica e apreendido na análise das monografias do Curso de Aperfeiçoamento de Oficiais (CAO).

10. O suporte para tal afirmação advém, sobretudo, da análise das monografias do Curso de A perfeiçoamento de Oficiais ( $C A O)$. A nossa pesquisa esteve restrita à A cademia de Polícia Militar (APM), não se estendendo à comunidade. 
$\mathrm{N}$ as relações da polícia com a comunidade, os valores do militarismo não deixam de estar presentes, porém, praticamente não colocam nenhuma barreira às práticas de truculência policial militar, reforçando o estigma sobre a corporação. Nas relações entre equipe dirigente e internos, apesar de haver hostilidades, o regulamento disciplinar revela-se coercitivamente, anulando ou abafando tais embates. No que diz respeito à relação entre Polícia M ilitar e comunidade não se pode fazer a mesma afirmativa, já que as hostilidades, cristalizadas sob a forma de truculência e violência policial, quase sempre não são sancionadas pelo R egulamento Disciplinar da Polícia M ilitar (RDPM /GO).

A o ser socializado numa instituição militar, - policial acaba por construir uma visão hierarquizada do civil, da mesma forma que aprende a distinguir quem é quem nas relações internas. De forma geral, o civil é visto como um paisano folgado, um termo que deprecia a condição de cidadão do indivíduo. No entanto, nem todos, sob a ótica policial militar, são vistos com desprezo, há aqueles que são vistos como superiores. Estes são aquel es poucos que, direta ou indiretamente, exercem influência na sociedade. A Polícia M ilitar não chega a incomodar essa minoria, pois os policiais militares sabem evitar complicações e punições desnecessárias. ${ }^{11} 0$ tratamento dos policiais militares é diferenciado para com os participantes da comunidade onde trabal ham. A queles indivíduos que se relacionam diretamente com 0 al to escalão do governo estadual, ou mesmo com 0 alto comando da Polícia M ilitar, parecem estar acima das leis. N esses casos, o jeitinho brasileiro aparece nas relações entre policiais militares e comuni dade, evitando e contornando praticamente todas as situações embaraçosas.

Dessa forma, nas relações internas da Polícia M ilitar, apesar dos embates e hostilidades, o regulamento ou o medo que ele impõe é necessário para manter a "ordem" dentro do quartel. Os exercícios militares e o próprio cotidiano dos policiais, sobretudo quando se trata

$\overline{11 . ~ E s s e ~ a s p e c t o ~ f o i ~ d e s e n v o l v i d o ~ n a ~ m i n h a ~ d i s s e r t a c ̧ a ̃ o ~ d e ~}$ mestrado - Praça Velho: um estudo sobre a socialização dos policiais militares -, na qual, a partir de DaM atta, discuto a questão da esperteza e malandragem policial militar. de uma instituição de ensino, fazem com que os policiais de baixa ou nenhuma graduação sejam completamente submissos aos superiores hierárquicos, quer queiram, quer não.

A relação entrePolícia M ilitar ecomunidade estrutura-se de forma distinta das relações travadas no interior dos quartéis. A pesar de ser o mesmo regulamento que prescreve as relações internas e externas da Polícia M ilitar, o resultado al cançado num caso não é o mesmo no outro. Esse fato pode ser constatado através da análise das fichas pessoais dos policiais militares como um todo, mas, em especial, nas dos praças. Verifica-se que as punições de caráter militar sobrepujam em muito àquelas referentes às relações entre Polícia M ilitar e comunidade. Raramente se encontram, nas fichas policiais militares, punições por motivo de espancamento, truculência ou desrespeito ao cidadão. Responder a um superior hierárquico constitui-se, na prática, uma transgressão mais grave do que violar os direitos humanos.

0 policial militar ésocializado num ambiente onde ele tem não só que obedecer às ordens de seus superiores e cumprir todos os regul amentos internos que prescrevem suas ações. 0 policial militar deve cumprir e obedecer de uma determinada forma, totalmente submisso e amplamente subserviente. Enquanto a submissão é prescrita nos regulamentos, a subserviência é fruto do abuso de autoridade de al guns membros da equipe dirigente.

\section{I deologia belicista}

A s disciplinas humanitárias introduzidas nos currícul os dos cursos de formação de policiais militares não anulam a ideologia belicista que norteia a formação e a prática policial militar. N essa visão, o criminoso étido como um inimigo que deve ser eliminado. Em vez da ação preventiva contra o crime, a palavra de ordem é a ofensiva, éa tomada de posição contra o inimigo.

De acordo com essa ótica, quanto menos bandidos, menos crimes; quanto mais policiais nas ruas, menos bandidos. Assim, o papel da Polícia Militar é tirar os criminosos de circulação, custe 0 que custar. ${ }^{12}$

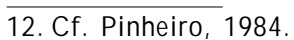


Essa ação militar contra o crime promove por si só a violência policial na medida em que o criminoso é visto como um inimigo e, portanto, combatê-lo não constitui crime. A final, em guerra só se vence aniquilando o outro. A inda nessa concepção, o confronto é intensamente buscado, já que não se trata de cidadãos que desviaram sua conduta dos ditames da lei, mas sim de inimigos perturbadores da ordem, de bandidos que estão colocando em perigo a vida em sociedade. São percebidos como verdadeiras aberrações que não podem ser toleradas no convívio em sociedade. Portanto, nada mais natural do que o comportamento violento e hostil dos PM s como forma de combate a tais aberrações.

Essa ideologia belicista que norteia as ações da Polícia M ilitar contra as práticas delinqüenciais firma-se na crença de que, para resolver a questão da violência e da criminalidade no B rasil, basta apenas mais do mesmo: mais viaturas, mais homens, mais armamentos e equipamentos. A umenta-se, assim, 0 aparato repressivo, sem, porém, mudar a estratégia de ação e a mental idade dos policiais militares. Os resultados práticos fomentados por essa ideologia belicista têm sido uma verdadeira guerra contra os del inqüentes. Guerra essa que assola e amedronta as classes populares, sem, no entanto, resolver os problemas da violência e da criminalidade tanto no meio urbano como no rural.

Os bandidos, de acordo com a ótica dos alunos do Curso de Soldado, são frios e calculistas. Por isso, muitos policiais militares afirmam não os respeitarem. Um dos alunos soldados, em entrevista, afirmou incisivamente que "bandido tem que ser erradicado. Você entendeu?! Caça um jeito aí! É cadeira elétrica, fuzilamento em praça pública. Eu sou a favor disso aí cara!". Um outro repetiu uma frase pronunciada pelo vice-comandante geral da Polícia M ilitar: "bandido bom ébandido morto".

Essa ideologia da guerra permeia os ensinamentos e a formação policial militar de tal maneira que nem mesmo a presença de um civil, o pesquisador/observador, pôde inibir o discurso de um oficial. Este, ao ser indagado a respeito da ação policial que resultou no massacre de Carandiru, respondeu que os policiais fizeram pouco, pois aquel es bandidos de São Paulo são uns monstros e não mereciam viver. A ssim, a forma de socialização imposta aos policiais militares não pode deixar de influenciar as práticas cotidianas do trabalho policial militar.

\section{Conclusão}

Como visto, as relações entre oficiais e praças são marcadas por hostilidades e arbitrariedades, sendo a humilhação verbal 0 recurso mais utilizado pelos participantes dos quadros superiores da instituição. A estrutura hierárquica e disciplinar da Polícia M ilitar não apenas deixa de inibir as práticas de abuso de autoridade dos superiores para com os subordinados como, em alguns casos, acaba por incentivá-las. I sso se deve, sobretudo, pelo fato de ser a equipe dirigente a responsável pelo julgamento das infrações disciplinares de todo quadro de funcionários da instituição, demonstrando, muitas vezes, parcialidade e corporativismo para com os superiores, em detrimento dos subordinados.

0 policial militar que se encontra nas posições mais baixas na escala hierárquica aprende, também, desde os primeiros dias de seu ingresso na instituição, a obedecer às ordens, vontades e desejos dos superiores, bem como a não revidar as humilhações sofridas. Tudo isso faz parte de uma aprendizagem não-formalizada, mas que não pode passar despercebida, sobretudo pel os alunos soldados.

A lém disso, o novo integrante da Polícia M ilitar passa, desde cedo, a representar o civil de forma pejorativa. A s constantes interações entre superiores e subordinados fazem com que os policiais construam uma visão hierarquizada das pessoas, estando o civil numa posição inferior à do militar, já que este último é portador de autoridade, enquanto aquele não. Essa visão hierarquizada, colocando o civil em desvantagem em relação ao militar, é o primeiro passo para a truculência policial militar, isto porque eles esperam que os civis se comportem como se fossem seus subordinados.

Dessa forma, as hostilidades entre equipe dirigente e internos, bem como a ideologia belicista que orienta a formação e a prática 
policial militar não podem ser descartadas como fatores explicativos do comportamento policial militar, em especial o violento.

\begin{abstract}
This paper is aimed at analysing the socialization process of the military police according to the concepts of a total institution and mortification of the self according to Erving Gof fman. W e take as a starting point the supposition that the socialization process of the military policeman, centered in the values and principles of hierardhy and discipline, dbes not take into consideration ancient values of its new members, forcing them to adapt to a new identity, based on military principles.

Thus, when undergoing socialization centered in hierardhy and military discipline, the new members construct a stereotyped vision of the civil citizens, considering them as lazy, which is a pejorative term. According to this perspective, the civil citizen begins to be represented in a pejorative way, which constitutes the first step for police violence.

In this way, a link between the socialization process and the stiffness of the military police towards the comminity is established.
\end{abstract}

K ey-words: total institution; Military Police; Socialization.

\section{Referências}

ALBURQUERQUE, Carlos Linhares de; MACHADO, Eduardo Paes. Sob o signo de marte: modernização, ensino e ritos da instituição policial militar. Sociologias, Porto A legre, UFR GS; ano 3, n. 5, jan./ jul. 2001.

BER GER, Peter L. Perspectivas sociológicas: uma visão humanística. 15. ed. Petrópolis: Vozes, 1995. [Col. A ntropologia, v. 1]

.; LUCKM A N N, Thomas. A construção social da realidade. 22. ed. Petrópolis: Vozes, 2002. .; BERGER, B rigitte. Social ização: como ser membro da sociedade. In: FORACCHI, M. M.;
M A RTINS, J . S. Sociologia e sociedade (leituras de introdução à sociologia). Rio de J anei ro: LTC, 1980.

CA STR 0, Celso. 0 espírito militar: um estudo de antropologia social na Academia Militar das A gul has N egras. Rio de J aneiro: J orge Zahar Editor, 1990.

DA SILVA, Telma Camargo. Soldado é superior ao tempo: da ordem militar à experiência do corpo como locus de resistência. Horizontes Antropológicos, Porto A legre, ano 4, n. 9, out. 1998.

GOFFM A N, Erving. A representação do eu na vida cotidiana. 8. ed. Petrópolis: Vozes, 1999.

Estigma: notas sobre a manipulação da identidade deteriorada. Rio deJ aneiro: LTC, 1988.

. M anicômios, prisões e conventos. São Paulo: Perspectiva, 1974. [Col. Debates Psicologia, v. 91]

LEIR NER, Piero deCamargo. M eia-volta, volver: um estudo antropológico sobre a hierarquia militar. Rio deJ aneiro: FGV, 1997.

PINHEIRO, Paulo Sérgio. Escritos indignados: polícia, prisões e política no Estado autoritário. São Paul o: B rasiliense, 1984.

Polícia e crise política: o caso das polícias militares. In: DAM ATTA, Roberto et al. Violência brasileira. São Paulo: B rasiliense, 1984.

RIFIOTIS, Theophilos. A denúncia da violência policial na imprensa de São Paulo: o leitor-modelo do caso da polícia mil itar na Favela $N$ aval (Diadema). In: OLIVEIRA, D. D. de; SANTOS, S. A. dos; BRITO E SILVA, V. G. (Orgs.). Violência policial: tolerância zero? Goiânia: Ed da U FG ; B rasília: M N DH, 2001.

SILVA, A gnaldo J osé da. Praça Velho: um estudo sobre o processo de socialização policial militar. 2002. Dissertação (M estrado em Sociologia) - Universidade F ederal de Goiás, Goiânia.

VELHO, Gilberto; ALVITO, M arcos (Orgs.). Cidadania eviolência. 2. ed. Rio deJ aneiro: Editora da U FRJ; FGV, 2000.

RECEBIDO EM NOVEMBRO DE 2003 A provado MARÇO DE 2004 